\title{
Gradhiva
}

\section{Ariela Epstein, À ciel ouvert. Cultures politiques sur les murs de Montevideo}

Rennes, Presses universitaires de Rennes, coll. « Des Amériques », 2015

\section{Michèle Coquet}

\section{(2) OpenEdition}

\section{Journals}

Édition électronique

URL : http://journals.openedition.org/gradhiva/3221

DOI : 10.4000/gradhiva.3221

ISSN : 1760-849X

\section{Éditeur}

Musée du quai Branly Jacques Chirac

Édition imprimée

Date de publication : 25 mai 2016

Pagination : 240-242

ISBN : 978-2-35744-093-7

ISSN : 0764-8928

\section{Référence électronique}

Michèle Coquet, « Ariela Epstein, À ciel ouvert. Cultures politiques sur les murs de Montevideo », Gradhiva [En ligne], 23 | 2016, mis en ligne le 25 mai 2016, consulté le 24 septembre 2020. URL : http:// journals.openedition.org/gradhiva/3221 ; DOI : https://doi.org/10.4000/gradhiva.3221

Ce document a été généré automatiquement le 24 septembre 2020.

(c) musée du quai Branly 


\section{Ariela Epstein, À ciel ouvert. Cultures politiques sur les murs de Montevideo}

Rennes, Presses universitaires de Rennes, coll. « Des Amériques », 2015

Michèle Coquet

\section{RÉFÉRENCE}

Ariela Epstein, À ciel ouvert. Cultures politiques sur les murs de Montevideo. Rennes, Presses universitaires de Rennes, coll. « Des Amériques », 2015, 172 p.

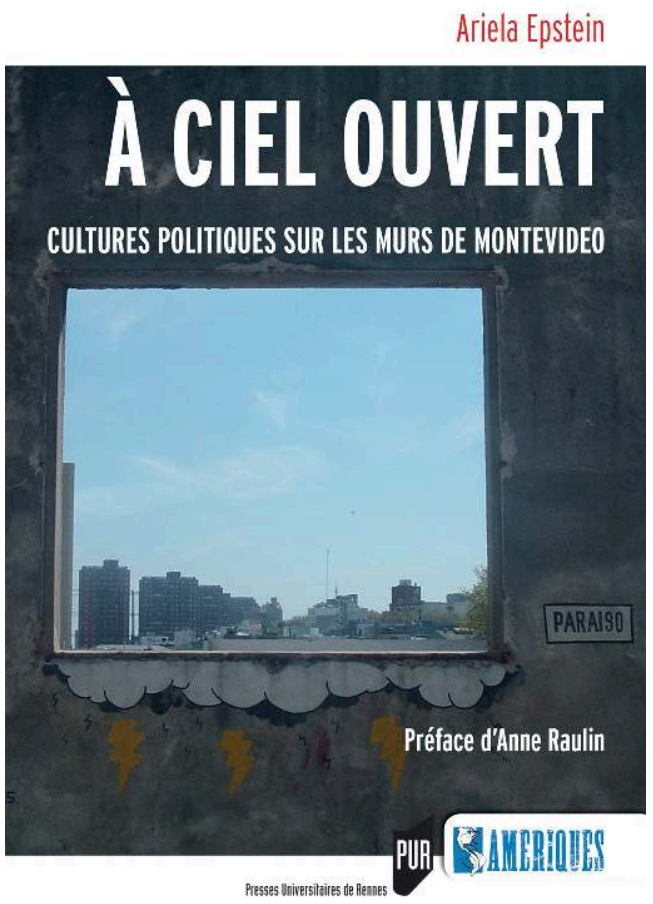


1 «Elle les regardait de haut, tendait vers eux le flacon de parfum Piver, Forvil, elle souriait dans quinze mètres de robe bleue. Le gril d'un soupirail trouait sa hanche. Il n'y avait pas d'autre image d'elle. » Fresque défraîchie, la publicité peinte que décrit Jean Échenoz dans L'Occupation des sols est le support d'une réflexion mémorielle sur une disparition en cours, celle d'un souvenir et d'une peinture mêlés, et sur l'entropie des villes. Loin de cette évocation nostalgique, l'ouvrage d'Ariela Epstein conduit son lecteur vers de tout autres images murales, les graffiti, peintures et inscriptions politiques de Montevideo, capitale de l'Uruguay, qui témoignent moins du temps qui passe que d'un présent actif et réactif, moins de la destruction et de la dégradation que de la dynamique positive d'une régénération continue de l'espace urbain par ses usagers.

2 Les images dont il s'agit ici relèvent d'une forme d'écriture du quotidien, à la fois individuelle et collective. À la différence de ce que l'on peut observer dans nombre de grandes villes d'Europe occidentale, les supports médiatiques recourant à la technologie sophistiquée de l'animation et du numérique ont encore peu investi les rues de Montevideo: les murs y demeurent les lieux traditionnels d'expression de cultures populaires, politiques, esthétiques et poétiques singulières, qui continuent à privilégier les graphismes tracés à la main tout en échappant en partie au processus d'artification du street art à l'œuvre dans les villes occidentales. Ce processus, paradoxalement, favorise l'exclusion de ces libres expressions, celles qui sont au cœur de l'ouvrage, perçues alors comme illégitimes par certains citadins et leurs élus. Comme le souligne l'auteur, les inscriptions murales de Montevideo restent remarquables à double titre, par leur diversité et leur capacité à perdurer et à résister à de nouveaux modes de communication.

3 C'est à la découverte de cette diversité qu'Epstein nous entraîne. Avec elle, le lecteur se fait promeneur et flâneur, parcourt les rues et les murs de Montevideo et apprend à la fois à déchiffrer les images peintes qui les couvrent, à connaître les pratiques militantes dont elles sont la manifestation, à rencontrer leurs acteurs, les habitants de la ville, à décrypter l'histoire et l'imaginaire politiques de l'Uruguay : la pintada, slogan politique sous forme d'une écriture murale de grande taille réalisée et signée par une organisation ou un parti, la leyenda, le graffiti « indiscipliné », les pochoirs, les graffiti constituent les grandes formes scripturaires du corpus étudié. La reproduction de ce dernier dans deux inserts en couleur permet au lecteur de suivre attentivement l'analyse qui lui est proposée. Ces inscriptions relèvent moins d'images figuratives que de mots dessinés ou de dessins écrits, un matériel graphique moins séduisant au premier abord que les productions du street art, où fréquemment prime la virtuosité gestuelle, chromatique et compositionnelle. Et c'est là un des tours de force du bel ouvrage d'Epstein que de nous restituer toute la profondeur sémiologique et anthropologique de ces écritures qu'elle qualifie de "langage passionné», ainsi que le pouvoir de fascination qu'elles exercent.

4 Les inscriptions murales de Montevideo témoignent de l'histoire nationale de l'Uruguay, une histoire écrite, dessinée, peinte et graffitée ; officielles ou officieuses, elles se suivent, se côtoient, se superposent, manifestant à ciel ouvert la structure dialectique de tout débat politique, les tensions de la ville, les débats idéologiques de ses habitants. La rue, nous précise l'auteur, est un des espaces où l'individu s'expose en tant que citoyen, assumant ainsi pleinement la définition du terme espagnol qui désigne tout habitant d'une ville, ciudadano, citoyen tout autant que citadin. L'histoire 
de la pintada se confond donc avec l'histoire politique de l'Uruguay ; manifestation des revendications des ciudadanos, ses apparitions et ses disparitions rythment les heurs et les malheurs de la démocratie uruguayenne. Déjà présente en Argentine sous le gouvernement Perón, la pintada apparaît en Uruguay dans les années 1950 à la faveur de mouvements ouvriers et étudiants, puis devient dans les années 1960, à Montevideo, le mode d'expression privilégié de l'extrême gauche et des membres et sympathisants du Mouvement de libération nationale-Tupamaros, jusqu'à l'avènement, en 1973, de la dictature civico-militaire qui en réprime durement les réalisations. La pintada bascule alors du côté de la clandestinité et de la résistance, et les murs deviennent une zone privilégiée de combat idéologique entre des positions de plus en plus radicales. Avec le retour du débat démocratique en 1985, les murs blancs de la capitale se recouvrent de pintadas et de graffiti où s'expriment tant les partis politiques que les individus. Mémoire graphique des luttes dont elle tire jusqu'à aujourd'hui son efficacité symbolique, la pintada est devenue la forme normale de propagande politique. Une efficacité enracinée dans la matérialité des pigments : les murs cachent encore dans les couches successives les traces des actions de deux générations de militants. La photographie d'un trou creusé dans ces strates (p. XVI, $n^{\circ} 32$ ) illustre la matérialisation dans le mur de cette sédimentation de leurs actes picturaux: "le temps se condense sur l'espace réduit des murs ", note Epstein. On pensera ici aux œuvres d'un Raymond Hains - les « at-trapes-mots» - qui prélevait des fragments bruts d'affiches collées les unes sur les autres où les gestes des passants, en les déchirant, avaient offert au regard des mots et des lettres enfouis dans l'épaisseur des feuilles, signes d'événements passés, de choses disparues et de gestes anciens.

5 L'ouvrage comprend deux parties. La première est consacrée à la pintada, pratique militante collective devenue, nous précise Epstein, le sceau du système politique uruguayen, une véritable institution dont elle analyse avec une grande finesse les modes d'agir et de penser des ses auteurs; la seconde s'intéresse aux formes plus récentes d'inscription urbaine, anonymes, généralement individuelles et non corporatives, fruits d'une nouvelle génération de "griffonneurs » des rues : leyendas, pochoirs, graffiti politiques et quelques réalisations relevant du street art. À travers les entretiens qu'Epstein a conduits auprès des membres des brigades des plus importantes formations politiques, se révèlent les enjeux individuels et collectifs de la pintada, des pans entiers de la vie de la brigade et, au-delà, de la vie politique montevidéenne.

6 La question du fondement agonistique de la pintada, que l'auteur, à la suite des militants, a désigné comme la «guerre des murs", introduit une réflexion passionnante sur la manière dont ceux-ci s'engagent, physiquement, dans le débat démocratique: elle définit cette pratique comme un "rite politique" renouvelé à chaque élection, un "rite de combat» et de construction identitaire. Les brigades disposent de deux armes principales : l'occupation des murs de la ville et les slogans qui y sont peints dont la portée, par le recours à une élaboration maitrisée à la fois du signifiant - dimensions des lettres, couleurs, formes... - et du signifié - les subtilités sémantiques contenues dans le message lui-même et la forme stylistique adoptée (palimpseste, métaphore, connotation...) -, est destinée à frapper les esprits. Recouvrement des pintadas des groupes adverses et surenchère, par occupations croissantes des murs, afin de montrer partout sa présence sont les deux moteurs de cette guerre. Dans l'affrontement entre brigades naissent des stratégies, des alliances et des rivalités aux règles changeantes selon que l'on est, ou non, en campagne. «Parce que c'est une lutte, dit un militant, en campagne, tu peins un mur et tu n'es même pas 
au coin de la rue qu'un autre vient derrière toi et te le recouvre, c'est à celui qui aura le plus de peinture» (p. 65). «Ce qui compte, souligne alors l'auteur, c'est de ne pas perdre les murs ", la pintada étant toujours réalisée sur une surface blanchie à la chaux, effaçant le message antérieur.

Peindre est donc l'acte collectif au fondement de la cohésion et de l'engagement des membres du groupe politique. Epstein déplie les différentes étapes de ce «dispositif rituel» (p. 34) que constituent la pintada et sa réalisation : en amont, l'invention du slogan, l'achat et la préparation du matériel, la commensalité, avant le moment fort du travail militant qu'est la sortie, la salida, où se négocient les zones à peindre, la surveillance des peintures déjà réalisées et des mouvements des autres groupes. Cette guerre des murs n'est pas exempte d'affrontements violents qui expliquent la faible participation des femmes aux salidas, une violence cependant plus symbolique que réelle, alimentée, en particulier, par la mémoire de la dictature, puis réactivée au moment de la campagne électorale, et puisant dans l'imaginaire d'un héroïsme de l'action politique.

L'auteur nous offre une étude très détaillée des stratégies discursives et iconographiques mises en place par les militants dans leurs slogans, autre face de l'agôn politique. Chaque parti, chaque sensibilité politique tente de trouver une tradition visuelle propre pour se singulariser: style graphique, nom et logo du parti, code chromatique repérable et identifiable de loin... Le slogan que médiatise la pintada doit être court. Sa brièveté ne fait sens pour le passant que parce qu'elle fait écho à celle des autres inscriptions politiques qui couvrent les murs au sein de ce que l'auteur nomme astucieusement une géo-graphie de la ville : chaque pintada n'est donc que le fragment d'un discours qui s'étend à tout l'espace urbain. Chacune investit le lieu où elle apparaît d'une charge sémantique et affective particulière. Cette forme brève permet la répétition, la possibilité de variations multiples et l'effet d'ubiquité. Son efficacité devient alors infinie. Comme l'a d'ailleurs montré Olivier Reboul, que cite Epstein, le slogan bloque le doute et l'incertitude au profit de l'action. « Un bon slogan réussit à donner à son destinataire l'illusion qu'il est son destinateur.» (Reboul 1975:24) Le tutoiement, le recours à l'argot, la familiarité de l'intonation propres au langage oral manifestent la proximité entre politiques et citadins : Gente como vos, « Des gens comme toi » (p. 42) ou Astori el FMI te aplaude y el pueblo se caga de hambre, "Astori, le FMI t'applaudit et le peuple crève la dalle » (p. 43). Le langage argotique permet d'exprimer la colère ou la frustration. Mais d'autres registres discursifs sont également utilisés pour signifier à la fois la singularité de la pintada et de l'idéologie du groupement politique qui en est l'auteur : l'ironie, l'humour, la joute oratoire, la connivence... La pintada relève enfin de la signature qui conjoint la fonction individualisante d'un nom propre, la saillance visuelle, l'effet de présence d'un signe personnel tracé à la main et la force d'un acte de langage (Fraenkel $2008: 17$ ).

9 Avec raison, Epstein sollicite les sciences du langage, l'analyse transtextuelle (Gérard Genette) ou la théorie du dialogue (Mikhail Bakhtine), ouvrant ainsi une piste aux développements multiples pour une approche à la fois anthropologique et linguistique des inscriptions murales. Le « dialogisme » domine la pratique langagière, puisque tout énoncé est pris dans un réseau d'interactions; tous les mots ayant déjà existé dans la bouche d'un autre énonciateur, nous parlons avec les mots des autres: «Chaque mot sent la profession, le genre, le courant, le parti, l'œuvre particulière, l'homme particulier, la génération, l'âge et le jour. Chaque mot sent le contexte et les contextes 
dans lesquels il a vécu sa vie sociale intense... » (Tzvetan Todorov cité par CalabreseSteinberg 2010) Poursuivant son entreprise d'anthropologie politique et urbaine, l'auteur embrasse à la fin de son ouvrage d'autres objets graphiques, leyendas, graffiti drôles, subversifs et railleurs qui mettent tout sur le même plan (politique, amour, drogue, sexe...), pochoirs et graffiti politiques: œuvres anonymes des jeunes générations, fruits souvent de gestes spontanés, personnels et en marge des organisations politiques, peuplant les interstices de l'espace urbain, ils brouillent les écritures médiatiques instituées et s'adressent au passant sur un mode complice. Plusieurs tonalités s'y rencontrent; sentimentale ou affective, transgressive, ironique ou humoristique, critique de la réalité sociale et désenchantée : Estamos dormidos, nos gusta no ver no pensar que todo esta mal, «On est endormis, on aime ne pas voir, ne pas penser que tout va mal» (p. 132). «La ville triste» (p. 130) : c'est ainsi qu'Epstein qualifie également l'âme de cette ville dont les inscriptions mêlent à la luxuriance et à la vitalité la mélancolie d'un petit pays «en crise d'identité ». Les "murs amers de Montevideo » (p. 126) disent également les douleurs de l'émigration économique, de la pauvreté et des espoirs déçus.

\section{BIBLIOGRAPHIE}

Calabrese-Steinberg, Laura

2010 « Esthétique et théorie du roman : la théorie dialogique du Bakhtine linguiste », Slavica bruxellensia 6 [en ligne], disponible sur : http://slavica.revues.org/348; DOI : 10.4000/slavica.348.

Fraenkel, Béatrice

2008 « La signature : du signe à l'acte », Sociétés \& Représentations 1(25) : 13-23.

Reboul, Olivier

1975 Le Slogan, Bruxelles, Éditions Complexe.

\section{AUTEURS}

\section{MICHÈLE COQUET}

michele.coquet@cnrs.fr 